\title{
Myocardial work - a modern tool to detect possible compensation mechanism of deformation in infective myocarditis with preserved left ventricular function
}

\author{
Stephan Stöbe ${ }^{1}$, Andreas Hagendorff ${ }^{1}$, Adrienn Tünnemann-Tarr ${ }^{1}$, Daniel Lavall ${ }^{1}$, \\ Matthias Gutberlet ${ }^{2}$, Ulrich Laufs ${ }^{1}$, and Bhupendar Tayal ${ }^{3}$ \\ ${ }^{1}$ University Hospital Leipzig \\ ${ }^{2}$ Leipzig Heart Centre University Hospital \\ ${ }^{3}$ Aalborg University Hospital
}

April 28, 2020

\begin{abstract}
The main direction of left ventricular (LV) contraction is based on the different architecture of myocardial fibers. Thus, it can be assumed that the specific analysis of different compounds of LV deformation might be a crucial diagnostic tool in patients with infective myocarditis (IM). This case report focusses on conspicuous findings of regional LV deformation in a patient with IM and preserved LV systolic function. Despite unspecific clinical symptoms in IM, e.g. subfebrile temperatures, cough, palpitations, suspect findings of circumferential and rotational deformation can be helpful to initiate further diagnostic procedures to confirm the diagnosis, e.g. cMRI or myocardial biopsy.
\end{abstract}

Case report - 832 (excluding title page, abstract, figure legends and references)

Corresponding Author:

Dr. med. Stephan Stöbe, MD

Department of Cardiology

University Hospital Leipzig

Liebigstraße 20

Leipzig 04103

Germany

Phone: +493419712464

Fax: +493419712659

Email: stephan.stoebe@gmx.de

Email: Stephan.Stoebe@medizin.uni-leipzig.de

Disclosure: The authors declare that there is no conflict of interest that could be perceived as prejudicing the impartiality of the case report. This research did not receive any funding.

\section{Hosted file}


20-04-27-Myocarditis-Echocardiography_Abstract.docx available at https://authorea.com/users/ 316095/articles/446310-myocardial-work-a-modern-tool-to-detect-possible-compensation-mechanismof-deformation-in-infective-myocarditis-with-preserved-left-ventricular-function

\section{Hosted file}

20-04-27-Myocarditis-Echocardiography_Manuscript.docx available at https://authorea.com/users/ 316095/articles/446310-myocardial-work-a-modern-tool-to-detect-possible-compensation-mechanismof-deformation-in-infective-myocarditis-with-preserved-left-ventricular-function 

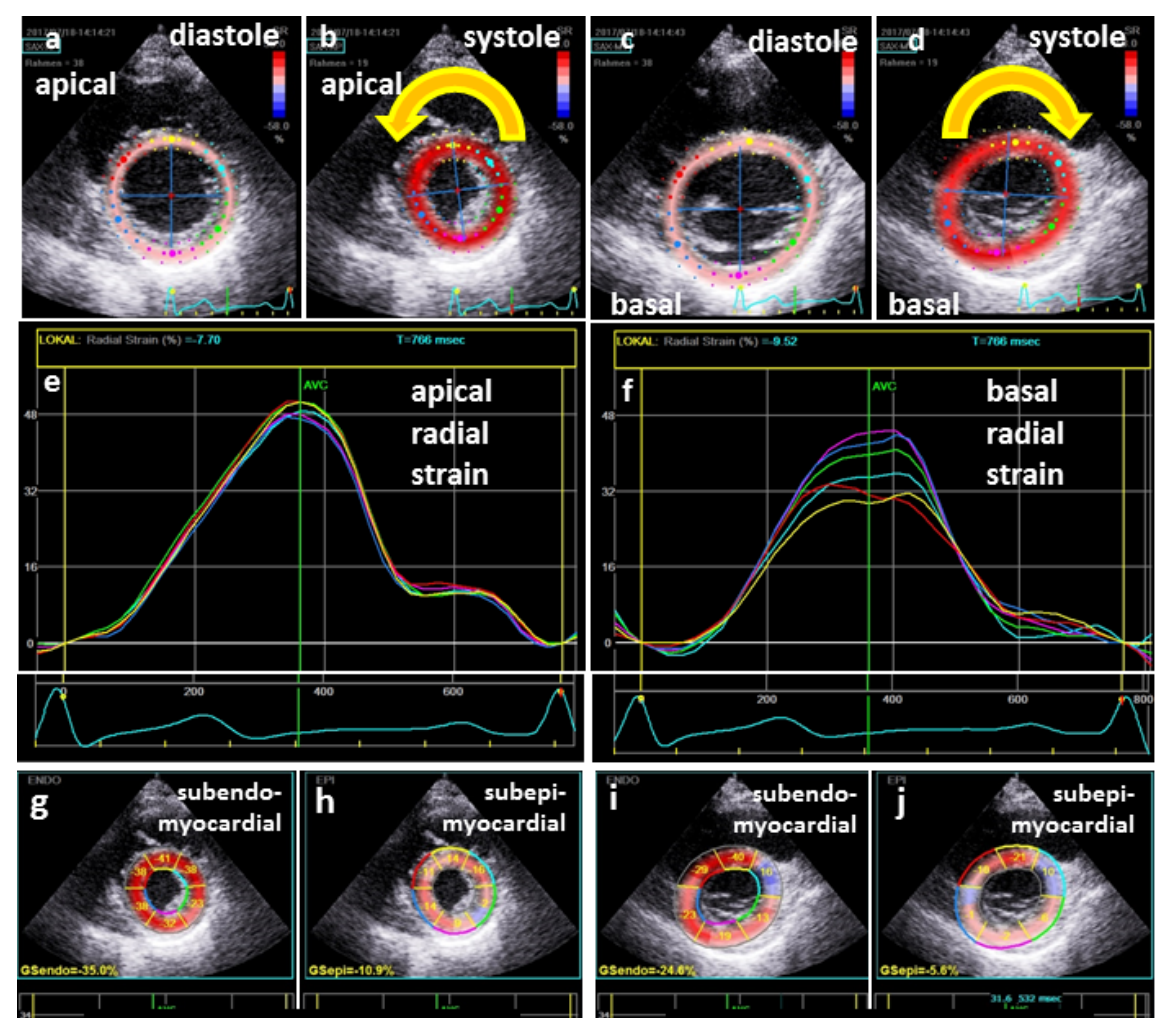
apical circumferential strain
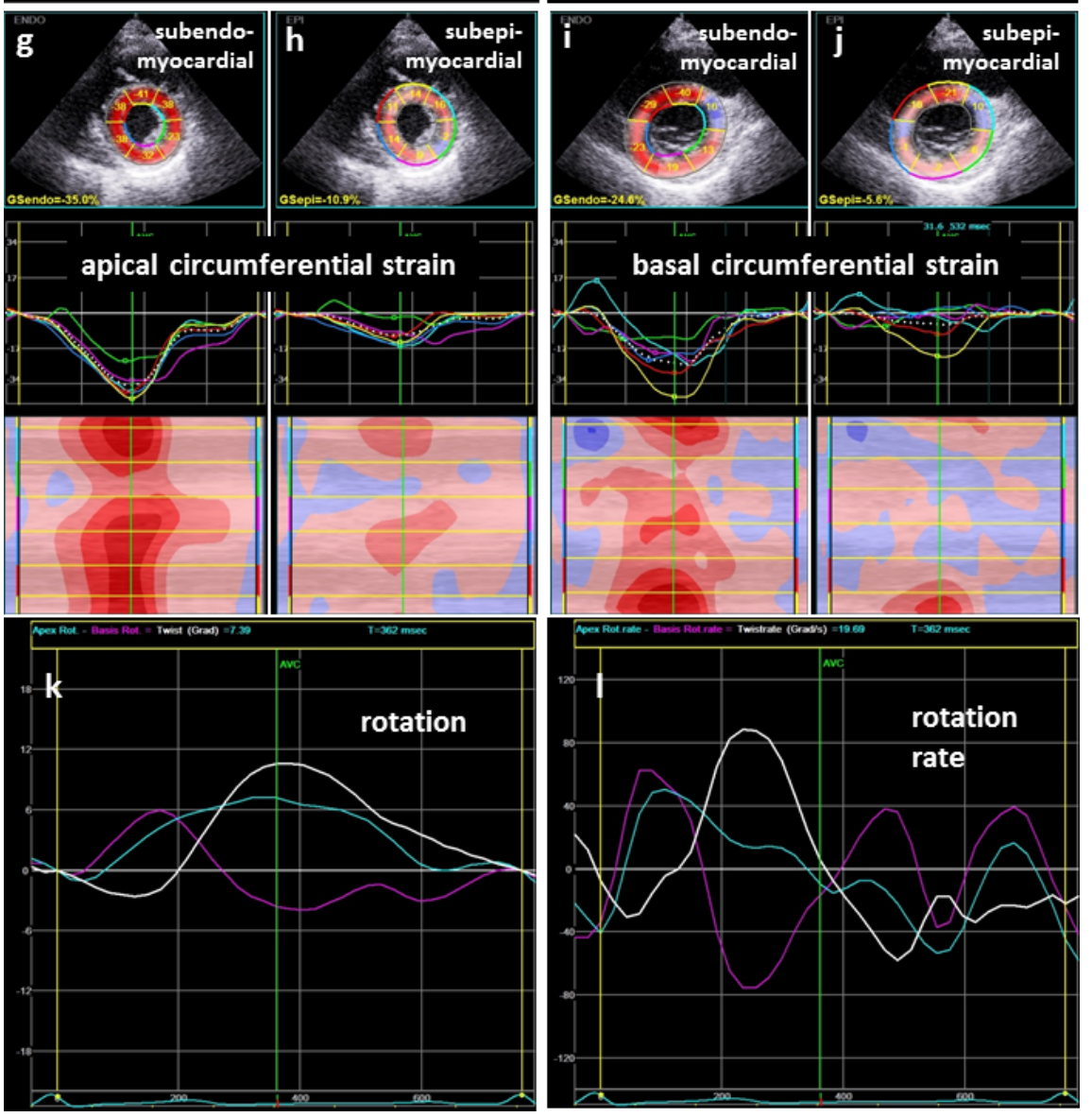


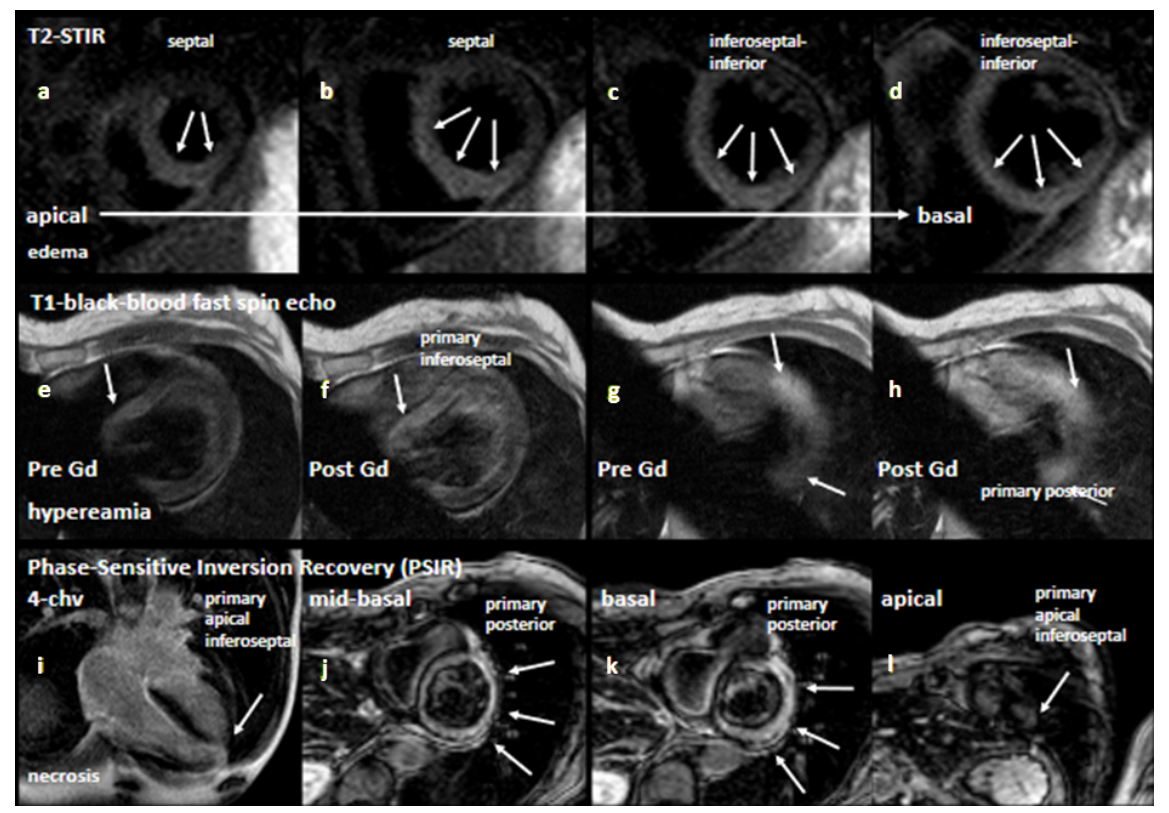



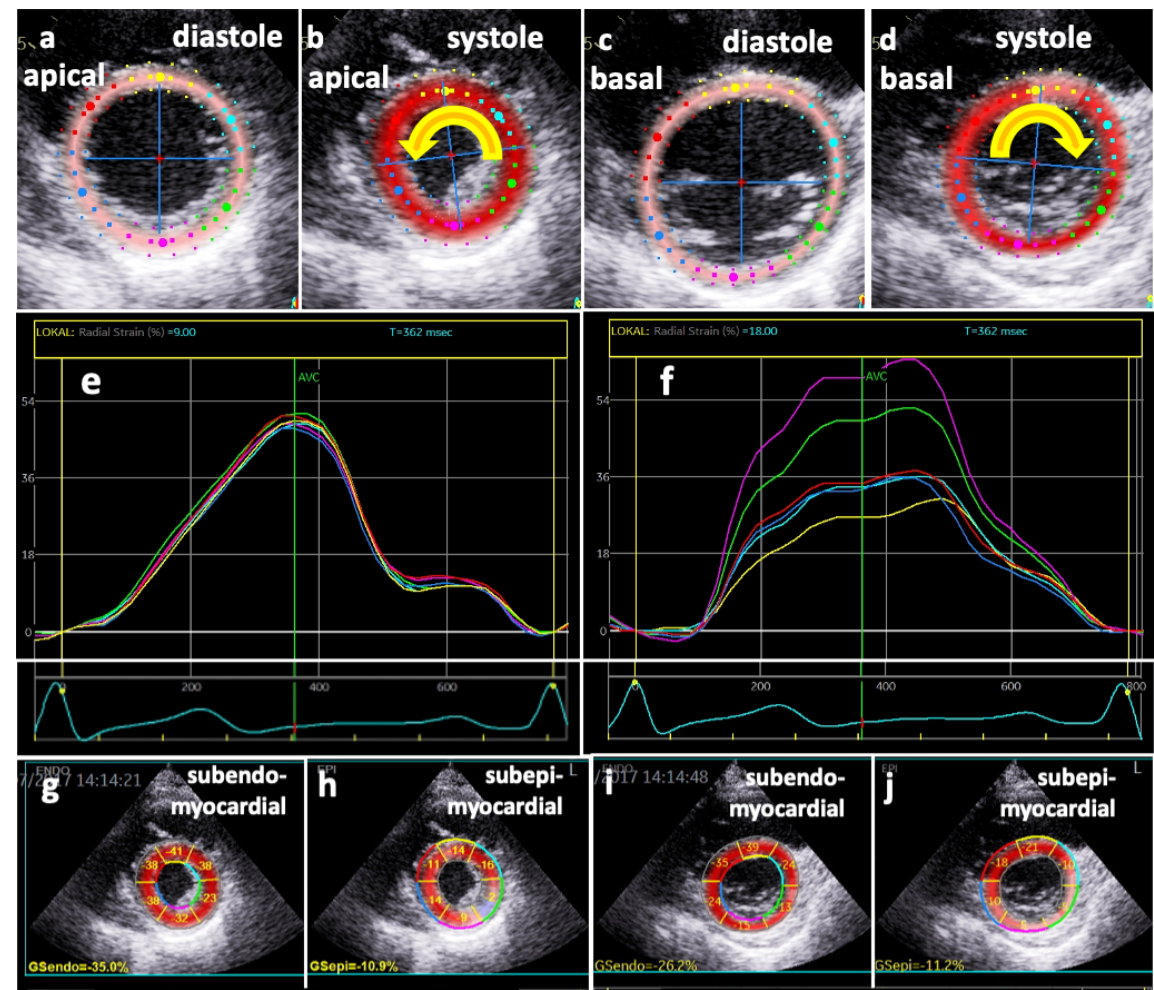

apical circumferential strain
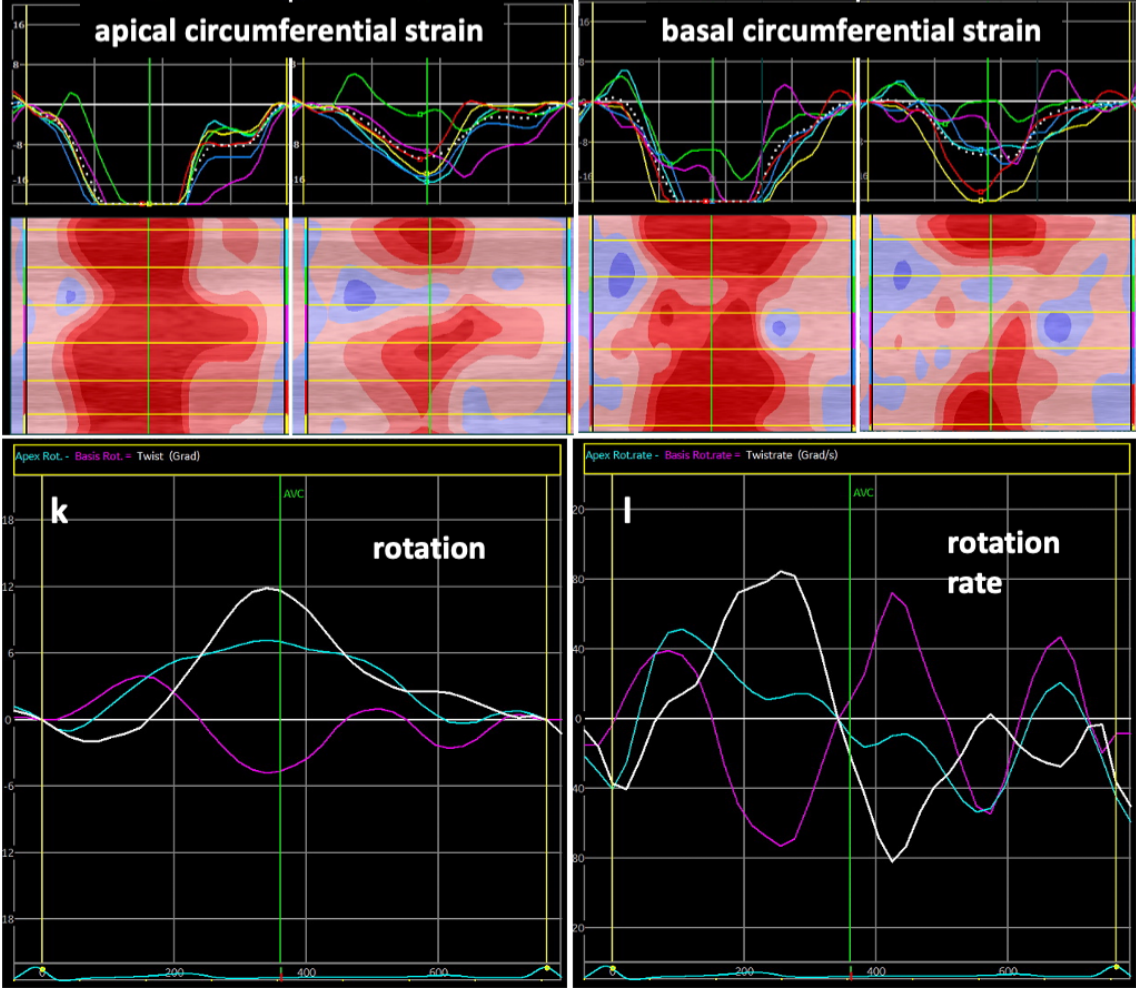

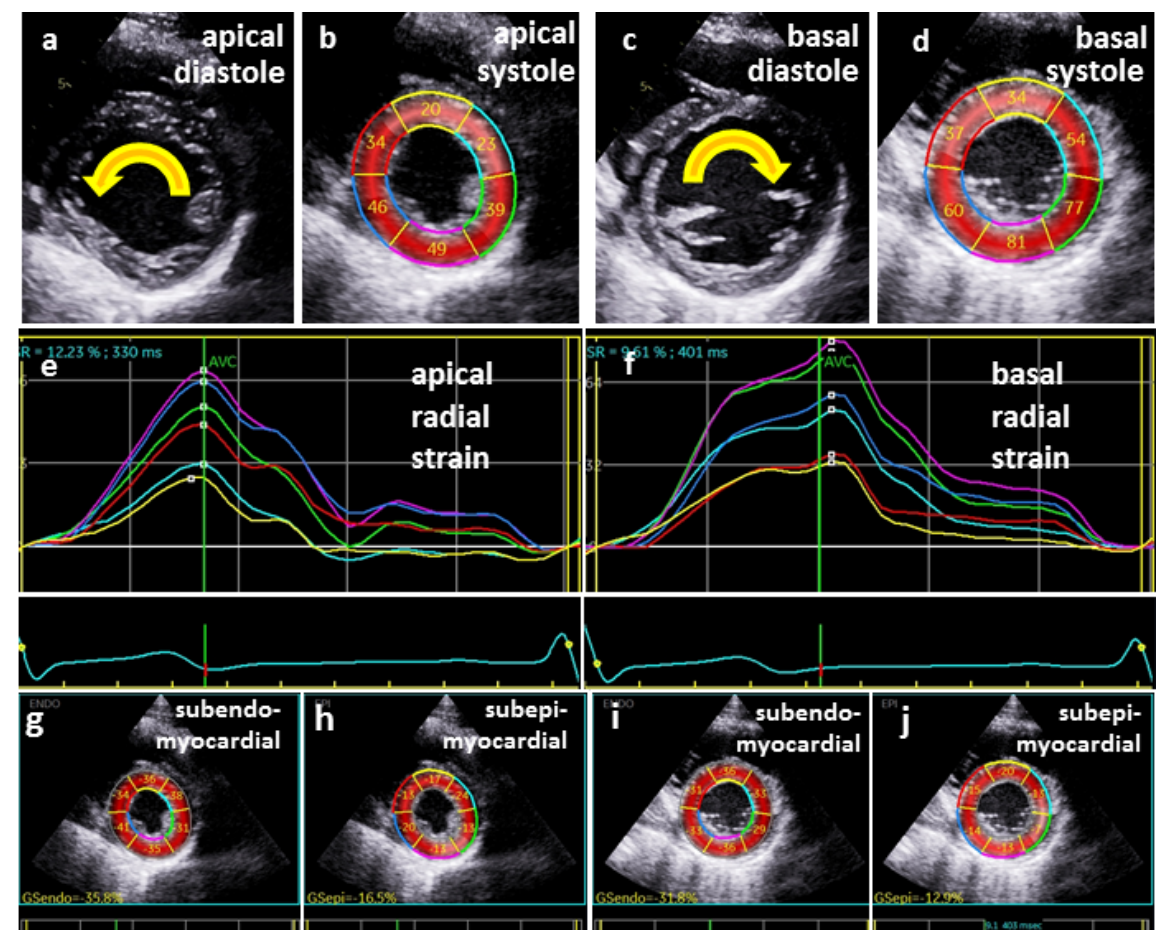

apical circumferential strain
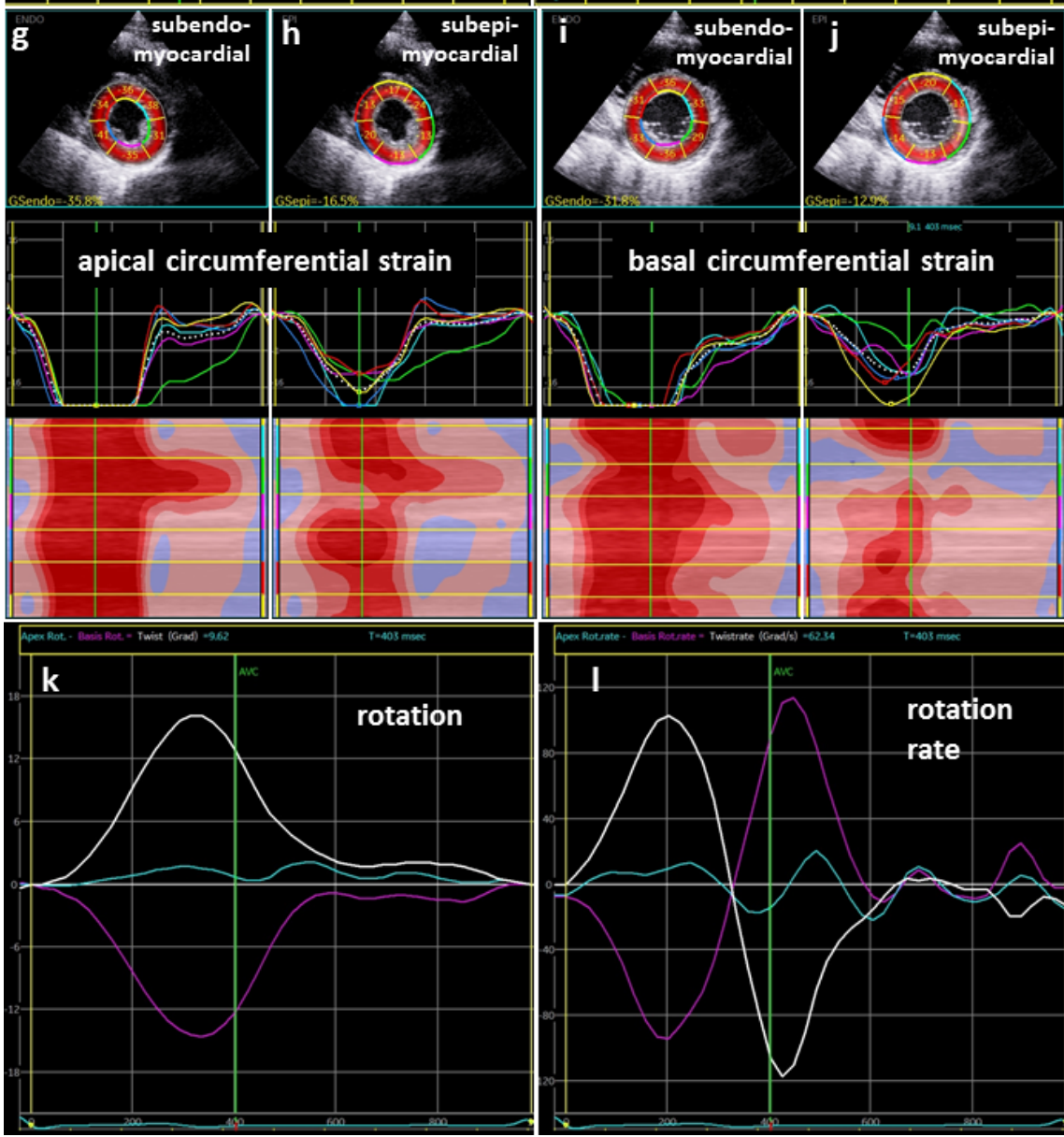

basal circumferential strain
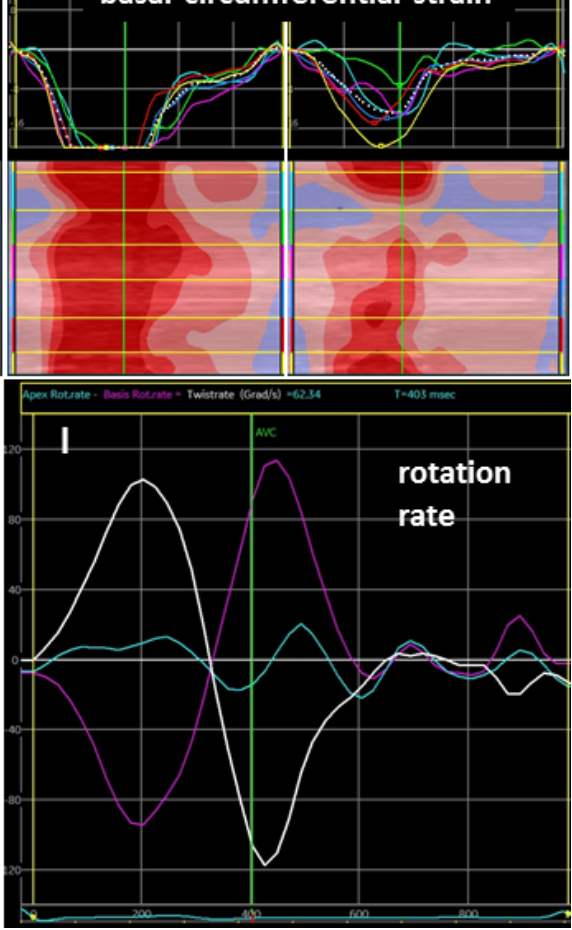

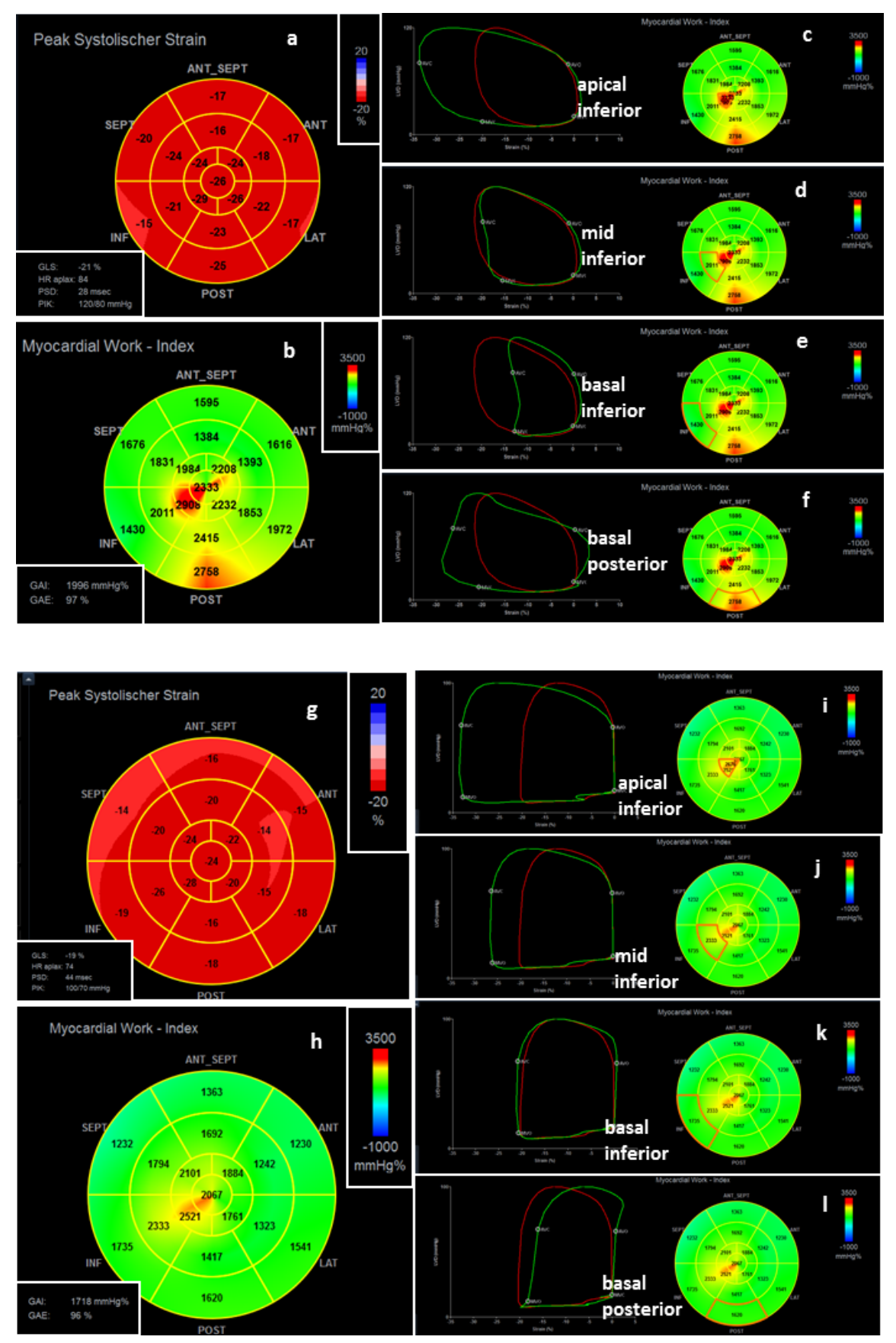